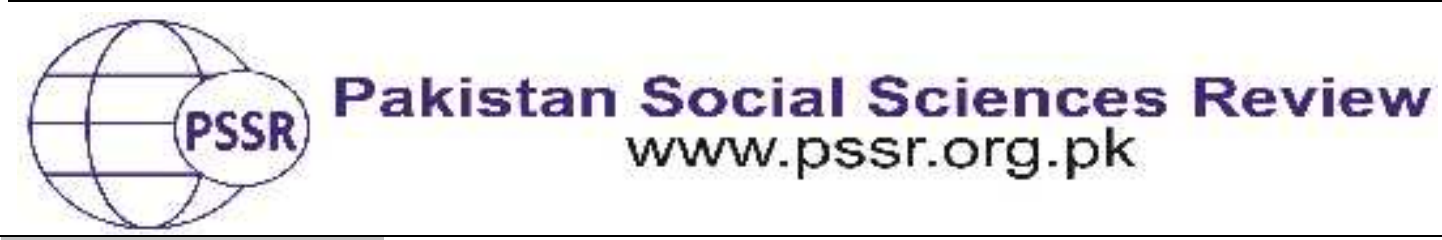

RESEARCH PAPER

\title{
Experiences of Pakistani Students in American Universities
}

\author{
Muhammad Akram ${ }^{1}$ Farrukh Munir ${ }^{2}$ Saira Taj ${ }^{3}$
}

1. Assistant Professor, Division of Education, University of Education, Lahore, Punjab, Pakistan

2. Lecturer, Institute of Education \& Research, University of the Punjab, Lahore, Punjab, Pakistan

3. Assistant Professor, Research and Evaluation Department, Lahore College for Women University, Lahore, Punjab, Pakistan

\begin{tabular}{|c|c|}
\hline & \\
\hline & \multirow{9}{*}{$\begin{array}{l}\text { The purpose of this study was to understand experiences of } \\
\text { Pakistani students' in American Universities. Open-ended } \\
\text { interviews were conducted by the first author of the study. } \\
\text { Fifteen participants were selected through convenience } \\
\text { sampling technique. Symbolic interactionism was followed as a } \\
\text { conceptual framework to situate the experience of Pakistani } \\
\text { students. Constant comparative method was used to generate } \\
\text { themes form the data. The study found that participants } \\
\text { experience lack of confidence due to language and culture, they } \\
\text { were unrepresentative of true personality, and they found their } \\
\text { teachers very helpful. The study also found that people in } \\
\text { American universities wanted to live in their zone of comforts, } \\
\text { they felt depressed when overloaded with assignments, they } \\
\text { were free exercise of their religious activities, and they were } \\
\text { never discriminated being Pakistanis. }\end{array}$} \\
\hline & \\
\hline & \\
\hline & \\
\hline & \\
\hline & \\
\hline & \\
\hline & \\
\hline & \\
\hline
\end{tabular}

\section{Introduction}

In this era of globalization, the knowledge is expanding in multi-dimensions and innovations and technological advancements are occurring frequently. It is the higher education that enables the individuals to become knowledgeable, distinguished, and up-dated about such innovations and advancements and to play their role for their country in getting a dignified place in the comity of nations. That's why every country is trying to provide best possible opportunities to its inhabitants to access to the higher education. One of the best ways of getting access to quality education is to visit foreign countries, especially the most advanced countries of the world, like America, that have earned repute through decades of continuous struggle in providing higher education and have highest standards of education. Looking at the importance of higher education, the Higher Education Commission (HEC) Pakistan is also taking keen interest in recruiting and sending the most eligible students to the foreign countries for getting higher education. Other than the 
UK, Canada, Australia, and New Zealand, thousands of Pakistani students visit American universities for study purpose. Thousands of candidates, who cannot get scholarship from the HEC, apply for Fulbright scholarships and get admission. Moreover, perhaps hundreds of students who belong to well-to-do families get admissions to the American universities without getting any scholarship.

Since studying in a foreign country is not easy and it involves numerous challenges, one requires a deeper understanding of the numerous problems and difficulties the Pakistani students face in American universities especially after the 9/11 incident. Though the selected candidates attend a couple of orientations after entering into the American universities and get familiarity with some of the initial problems, they must be provided, however, with all those supports that can help them meet the grave challenges.

Numerous researchers such as Sarkodie-Mensah (1998), Lee and Rice (2007), and Sherry, Thomas, and Chui (2010)have looked into the life of international students in the US, identified numerous problems, and given suggestions to minimize those challenges, if not eradicate them altogether, however, perhaps no study exits by now that could reveal the experiences of Pakistani students in the US. Since people coming from different countries bring different languages, ideologies, and varying political backgrounds, their needs, their challenges, and the levels of support to meet those challenges may differ from each other. It was imperative, therefore, to conduct a study on Pakistani students, who were currently studying in American universities, to get their experiences. The purpose of this study was to fill this gap and provide the policymakers, students, and their parents the experiences of those Pakistani students who are currently enrolled in American universities. The study explored the experiences of Pakistani students in the US as a main research question of the study.

\section{Literature Review}

We begin with the study of Sarkodie-Mensah(1998) who identified numerous problems the international students face in the US. For example, she stated that "there is hardly any study about international students in the U.S. that does not mention language as the major problem" (p. 218). She stated that "many college campuses offer accent reduction training for all international students and most especially for graduate teaching assistants and professors from foreign lands" ( $\mathrm{p}$. 220). Shefurther stated that "culture shock, social isolation, conditions/situations in home countries, cross-cultural relationships, financial difficulties, immigration laws and accompanying anxiety, employment for self and spouse, stress, and depression are examples of problems international students have to deal with" (p. 219). Sarkodie-Mensah (1998) stated that "the common trend is now for campuses to establish formal and informal networks that meet regularly to address the needs of students...[and] many college campuses offer orientations at least one week or a few days before classes start...counseling services, accent reduction training, teaching skills for graduate students, library resources are also used by many 
universities...[however] that every bit of information, even if it is repetitive, can only enhance a smooth transition" (p. 220).

Zhang (2013) conducted a case study to understand cross-cultural learning experiences of two Chinese students in American universities. The study identified the differences in culture, language, and social and political system between China and the US. The study further revealed that educators can assist students by becoming aware of their home culture, different learning styles, and in overcoming cultural shocks. Yeh and Inose (2003) stated that international students can experience many challenges as a result of language and cultural barriers, academic and financial difficulties, interpersonal problems and racial discrimination, loss of social support, and alienation and homesickness. Huang (2005) conducted a study on Chinese students with the focus of understanding their challenges in academic listening. The results revealed that lecture organization, use of textbooks, blackboard writing, lecture summary, amount of student participations, and amount of group work strongly affected their English academic listening.

Lee and Rice (2007) explored the experiences of international students at a research university in the U.S. Southwest. Based on the interviews of a sample of 24 students from 15 countries, they explored myriad difficulties the international students face in the US. The results showed that international students face difficulties such as "feelings of inferiority based on media portrayals or direct insults... hostility towards non-fluency in English, and discrimination and discrimination towards internationals, direct insults from their professors, interpersonal difficulties due to cultural intolerance, and problem in rehiring them due to discrimination.

Sherry, Thomas, and Chui (2010) examined the experiences of international students at The University of Toledo and highlighted the problems international students experience such as adapting to a new culture, English language problems, financial problems and lack of understanding from the broader University community. Le and Gardner (2010) explored the experience of Asian international doctoral students in the Science, Technology, Engineering, and Mathematics (STEM) fields at one research-extensive university. Their study revealed that students were often isolated from their peers and faculty, and they faced an array of issues including the lack of funding and the choice of advisor.

This briefly reviewed literature reveals myriad problems the international students have to face in American universities. Based on the literature, language problems, financial problems, culture chock, emerged as common themes, whereas choice of advisor, anxiety, stress, depression, and different learning styles emerged as uncommon themes. 


\section{Theoretical Framework}

We used Symbolic Interactionismas a conceptual framework to situate the experience of Pakistani students. In this study we tried to base our study on these assumptions. Firstly, through interviews, participant observation and document analysis, we attempted to examine the students' perspectives regarding their experiences while studying in American universities. Secondly, we looked into the meaning of things that emerged participants' social interaction with other. Thirdly, we handled those meanings through interpretive process. So we collected data from multiple participants to see the different angles at which they see the events.

\section{Material and Methods}

It was a qualitative study in which we interviewed fifteen participants. The authors used our "network" for participants' selection. The criteria used for the selection of fifteen Pakistani students were as follows: (a) The participants were fulltime regular graduate students in any American university, (b) they had been studying for more than one year, (c) they were not permanent resident of America, and, (d) they were supposed to return to their country after completing their graduation.

\section{Data Collection Procedures}

The data were collected through open-ended interviews. Firstly, the interviews were conducted with fifteen Pakistani students who were enrolled in American universities at graduation level. Fifteen graduate students were asked to participate in the study as interviewees, first through contact by electronic mail, then by Skype meeting. Interviews were audiotape-recorded to ensure accuracy of data reports (Bogdan \& Biklen, 1997). Semi-structured interview protocols were used for this study. Participants were asked questions such as "why were you interested in studying in the US", "what did you like in the very first week", "what you did not like during first week", "what has been challenging to you", "what has been rewarding for you", and "what differences do you feel between first and second year study".

\section{Results and Discussion}

In order to understand Pakistani student experiences in more depth, we interviewed fifteen volunteers. This paper relies extensively on the interview data. Interviews were tape-recorded, transcribed, and then analyzed by developing of a list of thematic codes based on an initial read of the transcripts. The initial codes were derived both deductively and inductively from the data. The codes were shifted and modified as we reread and rethought the data (Bogden \& Biklen, 1997; Marshall \& Rossman, 2014) in the manner of open and axial coding. Using constant comparative method the data were analyzed. Analysis permits the ethnographers to discover patterns and themes in the data to link with other patterns and themes (LeCompte \& Schensul, 1999). Through continuous rereading, rethinking, and 
rewriting (DeWalt and DeWalt, 2002), the researchers particularly looked to the data and tried to search those themes that could inform something to the research question.

\section{Findings}

The following themes emerged from data.

\section{Lack of Confidence due to Language and Culture}

One of the participants stressed on saying that she lost her confidence due to language problem while she came to the US. She stated:

I was just fluent in my country but I don't know when I came here I just lost my confidence... even you speak perfect sentence, the people don't understand that. So that was really challenging for me and that this is the main reason that I lost my confidence.

This finding was different from the findings of the previous researches. The previous researches have talked about language problems, here, however, we found that language problem affected on the participant's level of confidence. She further clarified that she did not think she was week in English, rather she stated that other people had problem with understanding her pronunciation. Replying to a question to pronunciation problem she replied:

Actually I thought they had problem; they don't understand me. I think that my pronunciation is like that's what we talk, but I think that is their problem; they don't understand me.

This point of view is quite novel as the non-native speaker of English language deems her language is good but the natives have problem in understanding.

She further clarified:

...these are two things, speaking and listening. In my listening I did not have any problem. Whenever professors use to deliver lectures, I understand very perfectly. But that I think the only problem is my speaking and because as I said we just take care of grammar rules, our whole concentration on these things, but here things are how to pronounce Rs or Ps these things. So that changes everything. So I have no problem with my listening but in speaking.

We can understand that she had some language problems, especially in speaking; however, the important thing is that this problem affected her confidence level that affected her socialization.

She stated: 
For the first time it is difficult for us and I was kind of personality that I don't use to talk to my class fellows and to share my problems, "Ok this is my problem". So I used to live in isolation.

\section{Unrepresentative of true personality}

Another participant stated that she was not representing her true personality. She stated:

Because of the language, I think that I am not representing my own personality. I am totally different personality in my country and here I could not express myself. The language problem was really challenging for me.

She meant that since other people had problem in understanding her pronunciation, that thing reduced her socialization with others; consequently she is representing a personality that is very much different from that of in Pakistan. She stated:

when I was in my university [in Pakistan] and I was student I was very social and I used to talk to my professors and...professors everybody used to know me who I was... I did not feel this thing [here]. In the class I used to sit and did not talk to anyone and so that was really it was not me. I was not that person.

\section{Teachers are helpful}

All the participants stated that teachers were very helpful in their educational problems. Participant 7 stated:

Now I really feel comfortable. Whenever I just get problem, I just get confused, I talk to my professors...I started communicating [in second semester] to my professors, to my class fellows, and that helped me a lot. [My professors] were really [helpful] and after the first semester I found them very helpful.

Participant 9 stated:

I used to observe people sitting in the professors' rooms and there was no formality between professors and the students [that] was really shocking for me. In our country there is a big gap between students and professors. Here people were really informal with their professors.

Another participant (3) stated:

I felt lucky to get good professors who had really pushed me to go for philosophy, pushed me to go for to different areas I did not have expect from, so in that aspect they have been very helpful, helpful in terms of suggesting the books, helpful in terms of marking papers quite flexibly, helpful in terms of appreciating whatever view you have and showing you what you don't see, helping you to resist and conceive the biases you come with. So in that aspect of course professors were very helpful. 
The participants were agreed that their professors were very much helpful in their academic problems.

\section{People want to live in their zone of comforts}

Another theme that emerged from the interviews data was about the comfort zone. Participants stated that they experienced situation in the US which was quite different from Pakistan. For example, participant 1 stated that:

I am not that much comfortable with people from here like from US. I am comfortable with people from Pakistan.

While coming to the US, participant 5 stated:

...in a way you were just going away from the comfort zone to a new zone, to a new place, to a new culture, to a new people for example to a new environment where you were expected something different and you expect different something from yourself as well as in term of your studies, in terms of your academic capabilities...

She stated that students think that the examinations would be the same as in Pakistan. But she found the entire education system different form Pakistan. She stated:

...the whole education system is different here. Obviously they are giving us more quality education. They meet standards, our standards don't meet here.

This finding shows that when people feel themselves out of their comfort zone, they expect and behave differently. Participant 4 stated:

In the first semester, there was a subject where we here the professors used to teach two chapters may be in just one class and that was challenging for me because in my country two chapters is a big thing that may take two weeks, and here I have to learn those, I have to study those two chapters in one day. So kind of difference I found in my country and here....but in the second year I just feeling much comfortable and I really enjoy with my fellows and I talk to them and....now I don't have problems to talk to someone... and now reading two chapters in one day is not a big deal for me.

Living in their zone of comfort, people compare things with those which are out of their comfort zone and try to meet the differences and challenges.

\section{Depression}

Majority of the participants stated that they experienced some kind of depression during their studies. One participant (8) stated:

I was really much depressed in first semester and I did not know that I am depressed. I said ok, this is the way this is the way I am. But when I was ok and I just felt different I was 
feeling good in second semester, then I came to know Ok! The first semester that was depression. I used to sleep a lot and whenever I just get depressed, I thought ok just go and sleep. You should think that I will sleep and I will get up and feel good but that was when I use to get up, and that was more depressing for me. So I just wanted to avoid going outside and wanted to sleep a lot and I just want to go for university I just use to go to class and then use to come back. But now when you are depressed when you are really depressed you don't know you are depressed because you feel this is the way when you live alone, but now I feel that ok, it was depression.

Participant 12 stated:

...most of the times like I remember I use to start reading the book, after reading a page, I would close it up, because closing the book up was the signature of my frustration...sometimes leaving the book, unread, sometimes coming out of room in frustration what could happen you know sometimes like keeping the book and then doing some another some activity in order to get myself back...yes. So this sort of things did happen with me while adjusting in the books.

\section{Free exercise of Religion}

The participants stated that they were free to perform their religious activities. They never had to face any difficulty in terms of praying, or celebrating their religious activities.

\section{Participant 2 stated:}

whenever we have religious festivals, let's say Eid-ul-Azha or Eid-ul-Fitr, we tend to be together, we perform prayers together, we offer prayers together, and sometimes we have dinners or lunches together, and sometimes we go to market together...yes....on Eid days the feeling you use to have especially when you are at home when use to be home with your brothers, sisters, though it is not the same but it gives the same feeling rather than being alone. You do enjoy, you do cook, you do try to color the days exactly the day you use to have at your home.

He was of the view that we celebrate our religious festivals as we are celebrating in our own home. Participant6 stated that on Eid days:

We get up early in the morning, try to shave, take bath, and go with friends for prayers, very much excitement, happiness, having the same feeling that it's Eid, wear new dresses or you know traditional clothes. We go together with friends to mosque for offering prayers. Once we are done, we meet, embrace everyone I mean those who we know, come back, after coming back then we usually have either lunches or you know different foods, chat, meet...yes, discuss, enjoy.

Participant 7 stated that their religious gatherings were a way of socialization for them. Talking about their celebrations and parties, she stated: 
Yes we have like different like whenever there comes some wishing days function like Eid function so we just invite each other at homes and we just cook different meals, and so that's our main parties and especially in mosques we have our community gathering so these are kinds of things that we say that's ok this is there I can have my social life.

\section{Difference between first year and second year study}

A Majority of the participants stated that there was a hell of difference between their first year and second year study. Participant 5 stated:

There is a lot of difference. In first year, I use to I was just waiting for the like I was just waiting for second year $O k$, that I just finish my graduation and I will go back to my home. In second year I have now dream to do PhD from here. So you can see the level of confidence that how much I am comfortable here and I feel I need to do PHD form here as this is really best place to do PHD. This is the main thing. You can feel the difference in first year and second year.

Participant 1 stated that she learnt how to deal with different educational problems: She stated:

Because the first semester experience through I just learned that it's Ok, how to study how to do study whatever the professors says.... whenever I used to get problem I used to go to my professors or I just consult my class fellows. It was not like...I was not in isolation. I started communicating to like my professors to my class fellows, and that helped me a lot. And still I always tell my juniors that whenever I get problem don't think that you are person you are going to solve it. You need to talk to someone; you need to talk to your professors.

\section{Participant 8 stated:}

it's difference of day and night... in the first semester... it was quite new how to settle and sail in the ocean to put into that way...start thinking how can I do my project or how can I design, though it takes time but sort of understand in what which book is what written from which perspective, what it says, how other perspectives would respond to it, I as a graduate students how should I take it, how should I situate myself in different academic theoretical frameworks, what suits me for example, these were the things which were quite unknown to me in my first year, which was night. And now I can sail through I can know for example no book is as much difficult... so it's day in that context. So things are appearing clear now.

The findings show that the participants were worried in the first semester about their study, grades, and assignments; however, as time went by, they learnt how to deal with their assignments and get good grades.

\section{Nondiscrimination with Pakistani Students}

Almost all participants stated that being a Pakistani student, they never has been ill treated by Americans. Participant 5 stated: 
...we have never been like in a feeling of unhappiness from professors' side or students' side, never...yes. But sometimes we do feel very much conscious. What is the situation in Pakistan let's say, how would it take, or what are the connections between the US and Pakistan....yes we all I think we know. But I have never been ill treated...yes...no never.

\section{Discussion}

The current study included fifteen interviews with Pakistani students who were currently enrolled in American universities, participant observation of Pakistani students, and data collected through documents accessed through Pakistan Student Associations in American universities. The following significant findings emerged: (a) Pakistani students felt lack in confidence due to language and cultural differences (b) they represented different personality due to language and cultural differences (c) they found their teachers very helpful (d) students wanted to live in their zone of comforts (e) they fell in depression when they did not know how to do their assignments (f) they freely exercised their religion and performed their religious activities $(\mathrm{g})$ they found great difference between their first year and second year study, and (h) they did not feel discriminated being Pakistani. The results of this study are aligned with the study of (Yan \& Berlin, 2009; Yeh \& Inose, 2003; Yuan, 2011).

This study, in overall, presents different findings from previous researches. Especially the effects of language barrier that lowers down the confidence level of students and, consequently, they underperform, and represent different personality from their original personality. The previous findings though found language as a common barrier; however, this finding of the current study is significant to deal with. Secondly, living in a zone of comfort is significant finding. It gives an idea that living in a comfort zone minimizes the challenges. If students take living in a new place as living in their comfort zone, they perform outclass. Thirdly, students were fully allowed to perform their religious activities freely. This is in concordance with the American constitution which allows everybody to exercise his or her religion freely. Discoveries from the current study augment the existing literature base by examining the experiences of Pakistani students in American universities. The findings would be helpful to policymakers in terms of providing language facilities to the Pakistani students before going to the US. Moreover, students and parents can have deeper understanding of the problems the students have to face while studying in the US. The authors recommend that Pakistani students should feel comfortable with people of other cultures and should participate in their functions to understand their culture, language, and dealings. 


\section{References}

Bogdan, R., \& Biklen, S. K. (1997). Qualitative research for education. Boston, MA: Allyn \& Bacon.

DeWalt, M. K., \& DeWalt, B. R. (2002). Participant Observation: A guide for fieldworkers. AltaMira Press: NY.

Huang, J. (2005). Challenges of academic listening in English: Reports by Chinese students. College Student Journal, 39(3), 553-570.

Le, T., and Gardner, S. K. (2010). Understanding the doctoral experience of Asian international students in the Science, Technology, Engineering, and Mathematics (STEM) Fields: An exploration of one institutional context. Journal of College Student Development, 51(3), pp. 252-264.

LeCompte, M. D., \& Schensul, J. J. (1999). Analyzing and interpreting ethnographic data: Volume 5 of the Ethnographer's toolkit. Walnut Creek, Calif: AltaMira Press.

Lee, J. J., \& Rice, C. (2007). Welcome to America? International student perceptions of discrimination. Higher Education, 53, 381-409.

Li, R. Y. \& Kaye, M. (1998). Understanding overseas students' concerns and problems. Journal of Higher Education Policy and Management 20(1), 41-50.

Marshall, C., \& Rossman, G. B. (2014). Designing qualitative research. Sage publications.

Patton, M.Q. (1980). Qualitative evaluation methods. Newbury Park, CA: Sage.

Prior, L. (2009). Using documents in social research. SAGE Publications. Washington: DC.

Pritchard, R. M. O., \& Skinner, B. (2002). Cross-cultural partnerships between home and international students. Journal of Studies in International Education, 6(4), 323354.

Sarkodie-Mensah, K. (1998). International students in the U.S.: Trends, cultural adjustments, and solutions for a better experience. Journal of Education for Library and Information Science, 39(3), 214-222.

Sherry, M., Thomas, P., \& Chui, W. H. (2010). International students: A vulnerable student population. Higher Education, 60, 33-46.

Yan, K., \& Berliner, D. C. (2009). Chinese international students' academic stressors in the United States. College Student Journal, 43(4), 939-960. 
Yeh, C. J., \& Inose, M. (2003). International students' reported English fluency, social support satisfaction, and social connectedness as predictors of acculturative stress. Counseling Psychology Quarterly, 16(1), 15-28.

Yuan, W. (2011). Academic and cultural experiences of Chinese students at an American university: A qualitative study. Intercultural Communication Studies, 20(1), 141-157.

Zhang, H. (2013). Academic adaptation and cross-cultural learning experiences of Chinese students at American universities: a narrative inquiry (Doctoral dissertation). Northeastern University. 